\title{
Numerical modelling of disconnectable turret mooring systems
}

\author{
A. Duggal, S. Ryu \& O. De Andrade \\ Research \& Development Department, SOFEC Inc., USA
}

\begin{abstract}
Floating, Production, Storage, and Offloading systems (FPSOs) have become a popular option for operators in almost all areas of oil and gas production around the world. The FPSO as a concept is the only production platform that has virtually no water depth limitations. When fitted with a disconnectable turret mooring (DTM) system, FPSOs can be used in areas where it is desirable to remove the production unit from the field temporarily to prevent exposure to extreme events such as hurricanes or large icebergs. This paper provides an overview of the key issues involved in the numerical analysis of a DTM for deep water. The paper focuses on the hydrodynamic loading and the global analysis of the FPSO system and the response of the various components during disconnection and reconnection of the system. The paper also makes direct comparison between the numerical analysis and the data obtained from model tests of the system with an emphasis on the impact of deep water on the analysis and design of such systems.

Keywords: fluid-structure interaction, FPSO, disconnectable turret mooring, floating platform.
\end{abstract}

\section{Introduction}

Disconnectable FPSOs have been employed by the offshore industry since the late 1980s in regions like the South China Sea and off North Western Australia that experience severe cyclones or typhoons. These early systems were typically small production and storage facilities in shallow water, but over the years have demonstrated the safety and effectiveness of such systems to disconnect and avoid cyclones. The JHN Lufeng FSO installed in 1993 in the South China Sea 
has disconnected and reconnected over twenty times over its life without incident.

In the late 1990s disconnectable turret mooring system (DTM) technology was exported to the Grand Banks off Eastern Canada, in a region notorious for extreme seastates and icebergs. The Terra Nova field was the first field developed in the region with a disconnectable FPSO, and resulted in a quantum leap in the development of the turret technology for high production (19 risers and umbilicals), automation, and quick disconnection and reconnection. This system differs from the previous DTMs as the turret mooring is designed to remain connected for the 100-year storm environment (significant wave height, Hs of $16 \mathrm{~m}$ ) but disconnect for icebergs and pack-ice. This system has been in operation for over five years and recently disconnected and reconnected for planned maintenance.

Currently the focus for development of disconnectable FPSOs is regions that experience severe cyclone activity like offshore North Western Australia and the Gulf of Mexico. The majority of these systems are for large field developments greater than 10 risers and umbilicals, and deep water. North Western Australia currently has two new disconnectable systems in operation and two more under construction. Forecasts call for additional three to five fields being developed with this technology in the next five years.

The Gulf of Mexico was devastated by hurricanes in 2004 and 2005 and this had led to increased interest in disconnectable FPSO technology, especially in ultra-deep waters. Currently there is one field being considered for development with a disconnectable FPSO, and the number could increase in the coming years. The technology applicable for the Gulf of Mexico is addressed in more detail in Duggal et al [1] and Luo [2].

The objective of this paper is to provide the methodology of numerical modelling of the FPSO, spider buoy, and various components with a focus on disconnect and reconnect operations. Validation of the developed numerical model is based on the comparison of numerical simulation results and from physical model tests. In addition, the important parameters related with extending disconnectable FPSO technology to deep water is discussed.

\section{Description of the disconnectable turret mooring system}

A number of disconnectable FPSOs are being developed for large fields in deep water regions. A typical disconnectable FPSO has a tanker shaped vessel with approximately one million barrels of oil storage, supporting a process equipment plant capable of producing and treating approximately 100,000 barrels of oil / day. Figure 1 presents the Santos Mutineer-Exeter FPSO, typical of a large field disconnectable FPSO offshore NW Australia.

The heart of the disconnectable FPSO technology is the disconnectable turret mooring system. A detailed description of the turret mooring system for the Terra Nova FPSO is presented in Howell et al [3]. Figure 2 presents a schematic of the DTM developed for the deep water Stybarrow field, offshore North Western Australia (to be installed in 2007). 


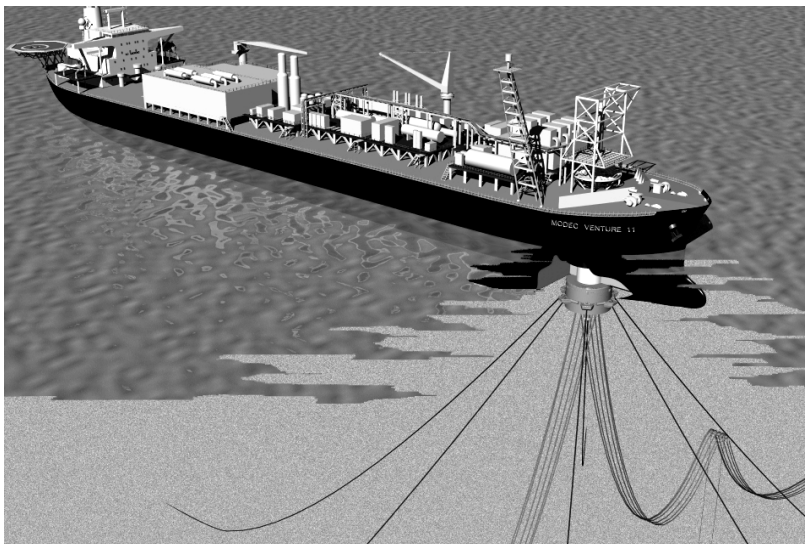

Figure 1: $\quad$ Santos Mutineer - Exeter disconnectable FPSO system.

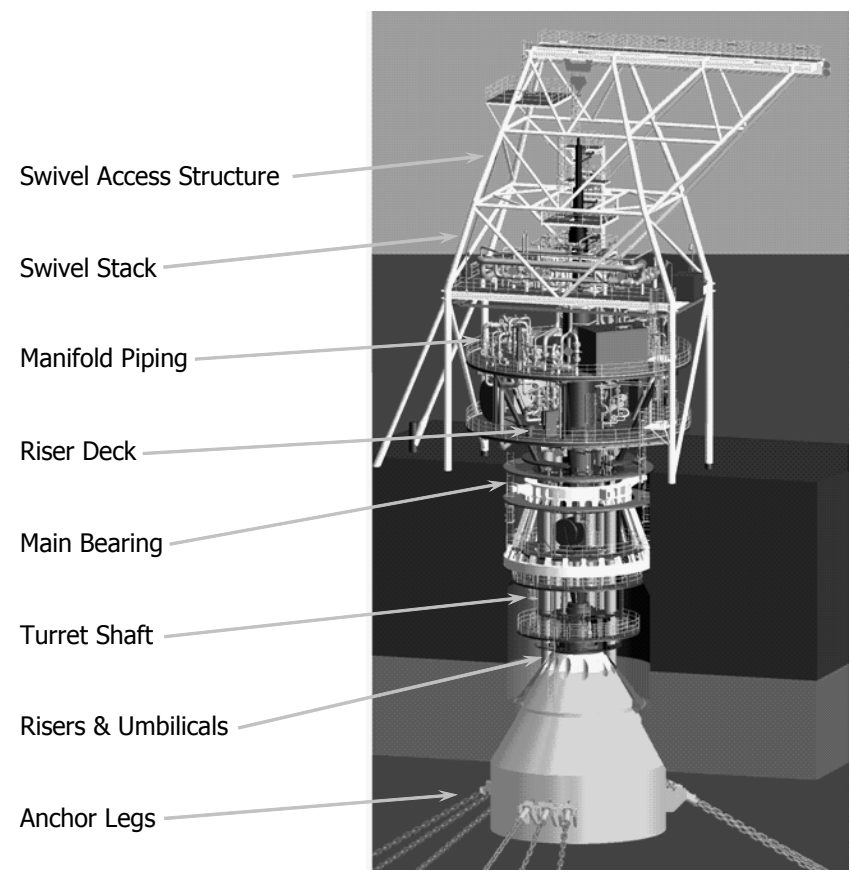

Figure 2: $\quad$ Stybarrow FPSO disconnectable turret mooring system.

The turret system serves as both a load-transfer and fluid-transfer system between the subsea system and the FPSO. The key components of the DTM are the disconnectable spider buoy, the turret shaft and bearing system that transfers the loads from the mooring to the vessel and allows passive weathervaning of the 
system, and the fluid and electrical swivel stack that allows transfer of fluids and electrical and control signals from the earth-fixed subsea system to the ship-fixed system. The disconnectable spider buoy is designed to allow quick disconnection in storm seas and supports the mooring and riser system about $30 \mathrm{~m}$ below the sea surface, allowing the vessel to sail away under its own power. Once the storm has subsided the vessel can return to the site and retrieve the buoy into the turret using equipment included in the turret system.

The disconnect and reconnect operation and timeline is summarized in Figure 3 which is based on an actual disconnection of the Santos Mutineer-Exeter FPSO offshore NW Australia during Cyclone Glenda in 2006. Glenda was a Category 4 storm when it passed by the field. The figure shows the operational watch circles that were used to prepare for disconnection based on storm intensity, projected path, and distance from FPSO. The blue circle (outer circle) is approximately $900 \mathrm{~km}$ radius and requires that the disconnect operation is set in process and non-essential personnel are evacuated when the cyclone crosses the boundary. The yellow watch circle (inner circle) is approximately $750 \mathrm{~km}$ in radius and is the 12-hour shutdown window where all production is stopped and the risers lowered for disconnection. The red watch circle (middle circle) is approximately $450 \mathrm{~km}$ in radius, and once the storm enters this circle the system is disconnected and the vessel sails to a designated safe zone. The spider buoy then supports the mooring and riser system and is designed to ensure the integrity of the system in the 100-year cyclone environment. Once the storm has passed the vessel returns and retrieves the spider buoy using the winch system in seastates up to $3 \mathrm{~m}$ significant.

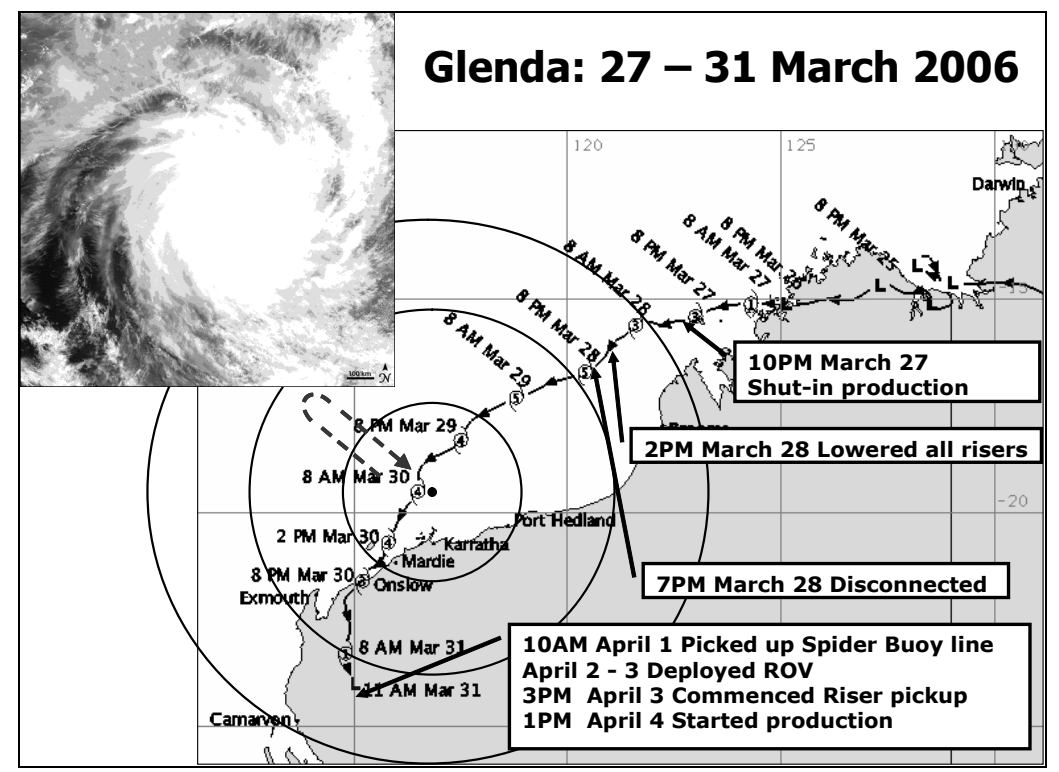

Figure 3: Watch circles and timeline for disconnection during Cyclone Glenda. 
The efficiency of disconnect and reconnect operations for disconnectable FPSOs is an important aspect of the design of the system. From a system analysis viewpoint this requires detailed numerical analysis and physical testing to develop responses, loads, and operational criteria for the two operations to proceed safely. The analysis and verification of the results for disconnect and reconnect operations form an important part of this paper. Global analysis of the FPSO system when connected to the spider buoy and anchor leg system will not be addressed in this paper. Duggal et al [4] provides a detailed description of the analysis of such a system for the Terra Nova field.

\subsection{Design considerations for deep water DTM systems}

The design of deep water DTM systems has some important design considerations that are usually not an issue for deep water permanent mooring systems. One key parameter is the mooring and riser payload on the disconnected spider buoy as it dictates the required net buoyancy of the spider buoy, and thus its performance. This requires an anchor leg and riser design that is optimized for a disconnectable system in addition to the performance required for the connected FPSO.

Anchor leg payload can be controlled by using mooring support buoys in each anchor leg or using polyester rope segments. The optimization of the vertical stiffness of the mooring system that governs spider buoy drop speed, target depth of the spider buoy when disconnected, and maximum pull-in loads during reconnection is another important consideration. The riser configuration also needs to be designed to specifically result in a low payload with a riser tower arrangement being an optimum configuration for deep water. Lazy wave risers with high arches have been deployed for the Stybarrow DTM in $825 \mathrm{~m}$ of water.

Another related issue with riser payload is the contents of the risers at various stages of installation and operation. Typically during riser installation the risers are water filled resulting in the maximum possible payload on the spider buoy. During operation the risers may be gas or product filled, with the product possibly being a mixture of crude and gas. During disconnection the mixed product contents will separate into gas and oil, resulting in a variable payload. These variations in payload require the spider buoy to have the appropriate net buoyancy and so a complex ballasting system must be provided.

Another important aspect of the system design is the consideration of hydrodynamic loading on the spider buoy both in the connected and during various stages of disconnection and reconnection. Accurate knowledge of this loading allows proper estimation of extreme and fatigue loads on the turret system and accurate estimation of operational limits for disconnection and reconnection. The calculation of the buoy responses for deep water systems is more complex than the shallow water DTM applications as the coupling between the spider buoy, mooring and riser systems becomes more important as the water depth increases. This is because the inertia and drag/damping of the spider buoy becomes relatively smaller compared to that of mooring and riser system (Ryu et al [5]). 


\section{Numerical modelling and verification}

To design an FPSO with a DTM system, four main design cases must be addressed: (1) spider buoy connected to FPSO, (2) transient spider buoy disconnection from, (3) spider buoy reconnection, and (4) spider buoy survival in extreme cyclone environment. This paper focuses on the modelling of the DTM system for the various stages of disconnection and reconnection for the Stybarrow FPSO.

The Stybarrow FPSO is located in an average water depth of $825 \mathrm{~m}$. The environment is characterized by strong swells from the south west, and severe cyclones during the months of January through April. The nine anchor legs for the FPSO vessel are arranged in three groups of 3 anchor legs each. The riser system consists of 10 lazy-wave risers and 2 umbilicals. The spider buoy has a total displacement of 1400 MT with a net buoyancy of 650 MT to support the maximum mooring and riser payload.

The analysis of the DTM system uses both time and frequency domain numerical models. The vessel and spider buoy hydrodynamic analysis is performed using the program WAMIT. Global analysis of the FPSO and mooring / riser system is primarily performed using the Seasoft software suite. Time domain analysis is conducted with the program OrcaFlex. Model tests at two scales were conducted in an ocean basin to derive some hydrodynamic coefficients of the spider buoy during disconnection, and to provide data for verification of the numerical models.

\subsection{Hydrodynamic model of FPSO and spider buoy}

Calculation of hydrostatic coefficients, added mass and potential damping coefficients, first-order wave exciting forces/moments, motion RAOs, and drift forces/moments were performed by using a radiation/diffraction program WAMIT. WAMIT is also used to calculate the hydrodynamic pressure field and corresponding total hydrodynamic loads on the spider buoy both connected and disconnected from the FPSO. Figure 4 shows an FPSO panel mesh for hydrodynamic calculations. Figure 5 illustrates the normal vectors of each panel with pressure strength in size around the spider buoy connected to the FPSO.

Calculation of the hydrodynamic forces on the spider buoy when connected to the FPSO is important for the turret mooring system design as these forces can be of similar magnitude to the combined mooring and riser load. This has a large impact on the structural and mechanical design of the turret mooring system for both extreme and operational seas. In addition to diffraction and radiation loads drag loads on the buoy and hull were also considered.

The drag and inertia coefficients of the spider buoy when dropping from the turret were estimated by performing a series of experiments with and without the turret at two different scales (1:35 and 1:81) as shown in Figure 6. This allowed determination of the scale effects and also "tuning" of the 1:81 model of the turret and spider buoy (including flow into the lower turret) for later use in the ocean basin tests with the FPSO and complete mooring and riser system. 


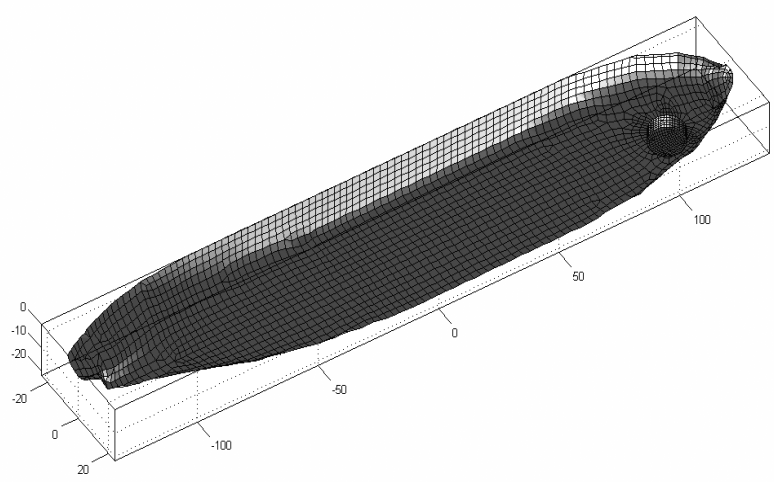

Figure 4: $\quad$ Mesh used for hydrodynamic calculations (bottom view).

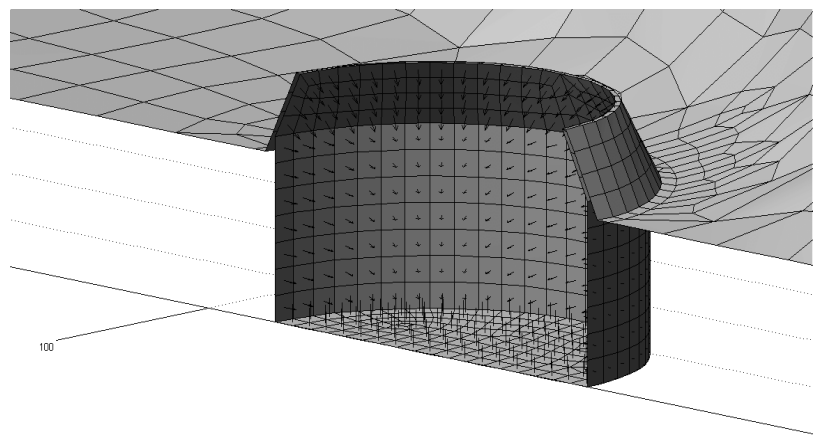

Figure 5: Presentation of normal vectors of each panel with pressure strength.

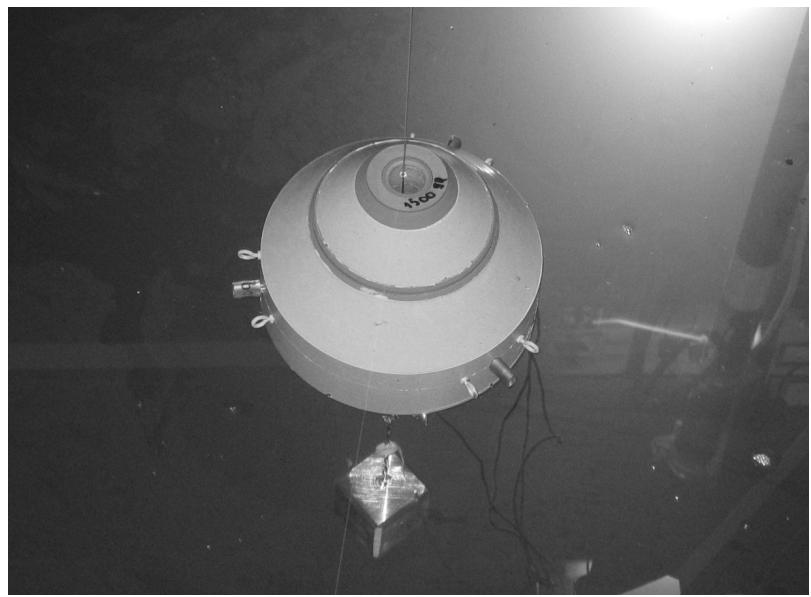

Figure 6: $\quad$ Spider buoy with a clump weight for the drop tests. 
68 Fluid Structure Interaction and Moving Boundary Problems IV

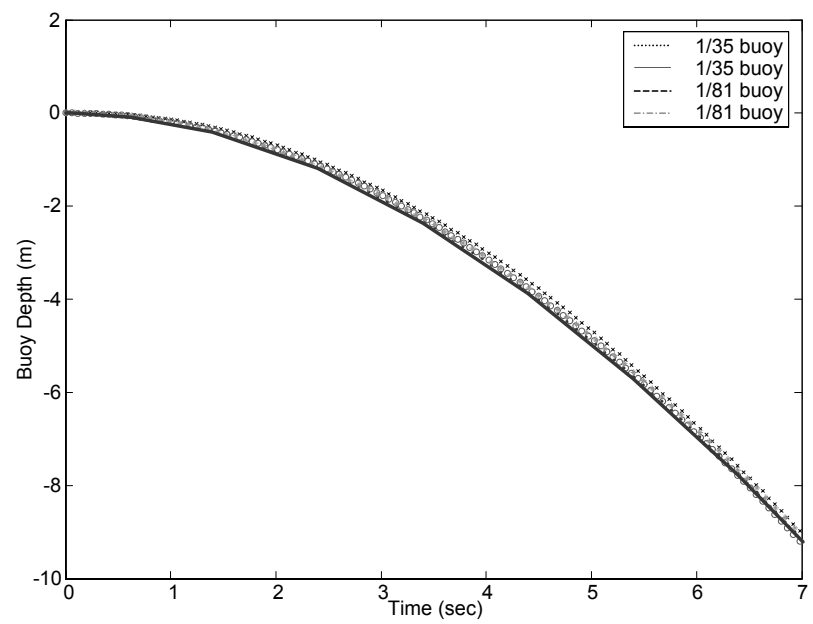

Figure 7: $\quad$ Buoy drop depth comparison between model test (markers) and prediction (solid line).

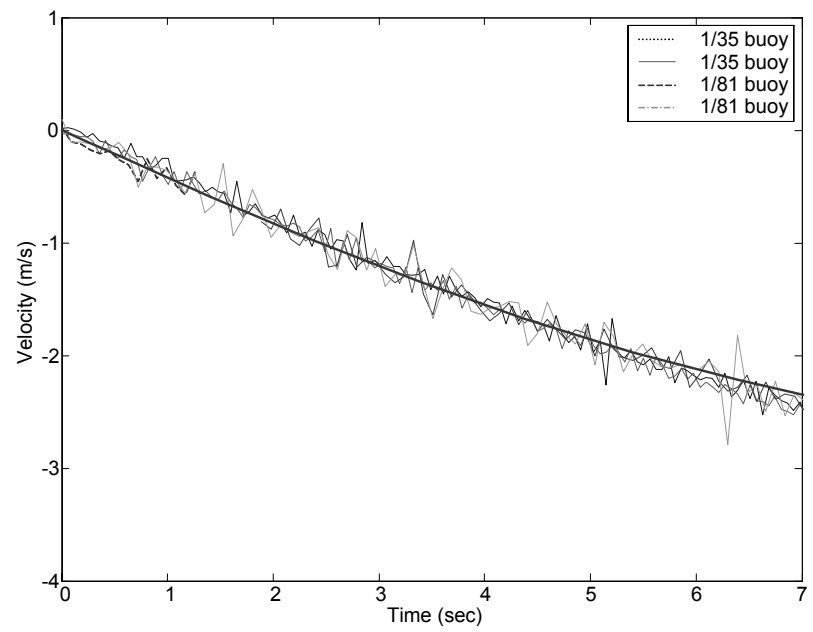

Figure 8: $\quad$ Buoy drop velocity comparison between model test (fluctuating lines) and prediction (smooth line).

The buoy drop depth and velocity comparison between model test and calculation results are shown in Figures 7 and 8. The agreement is seen to be excellent. Estimated inertia and drag coefficients are $\mathrm{Cd} n=1.0$ (normal direction), Cd_a $=0.9$ (axial), and $\mathrm{Cm}=0.60$ (inertia).

To take into account the drag and added mass due to the shape of the spider buoy, the spider buoy was made of a stack of multiple discs as shown in Figure 9, allowing different $\mathrm{Cd}$ and $\mathrm{Cm}$ coefficients for each disc. Figure 10 
presents an elevation view of the numerical model used to study the spider buoy, mooring and riser system for the various disconnect and reconnect analyses.

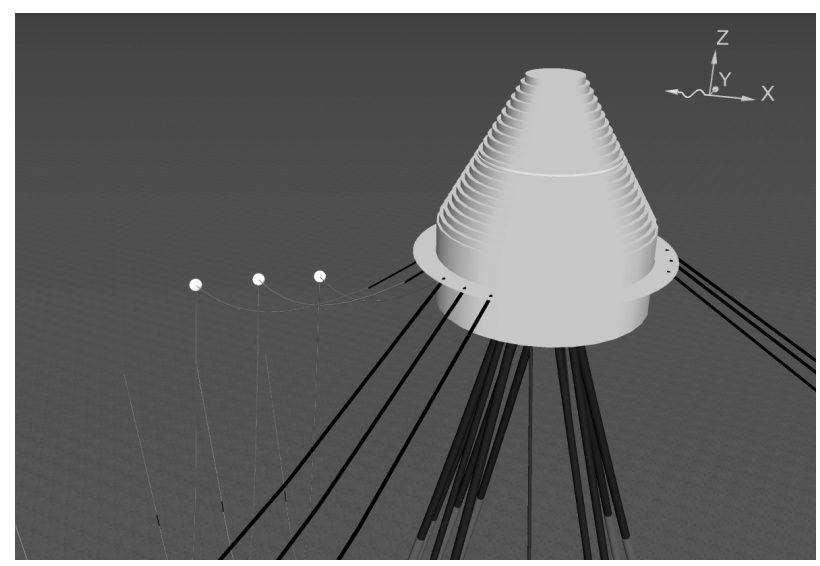

Figure 9: $\quad$ Representation of the spider buoy in the numerical model.

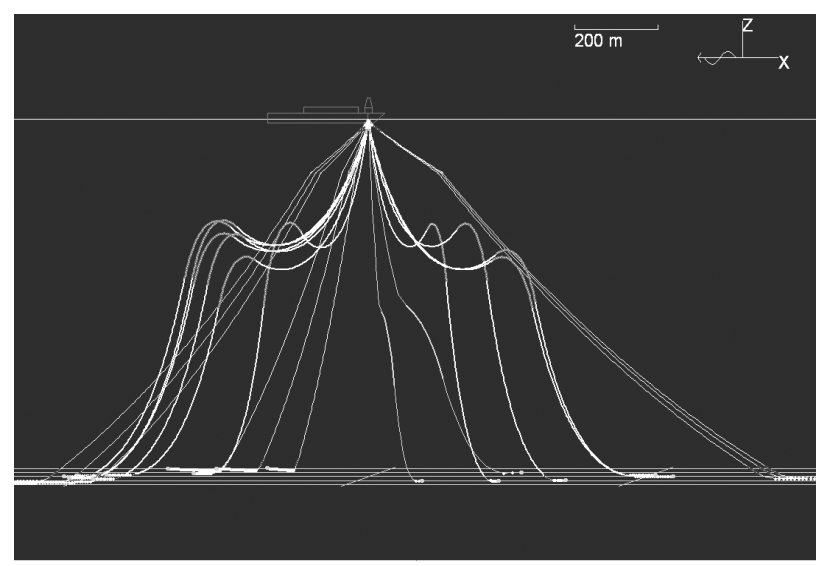

Figure 10: FE model of the entire spider buoy system.

\subsection{Transient spider buoy disconnection}

Time-domain simulations were conducted with the spider buoy system model connected to the vessel in regular waves with height of $10.2 \mathrm{~m}$ and period $15.4 \mathrm{~s}$. The buoy was released at a pre-determined time and allowed to freefall. Figure 11 compares the predicted response to the results of the two model test runs conducted with the same parameters, and the comparison is seen to be excellent. This simulation and test demonstrate the capability of the DTM to disconnect in severe seastates without any interference with the vessel. 


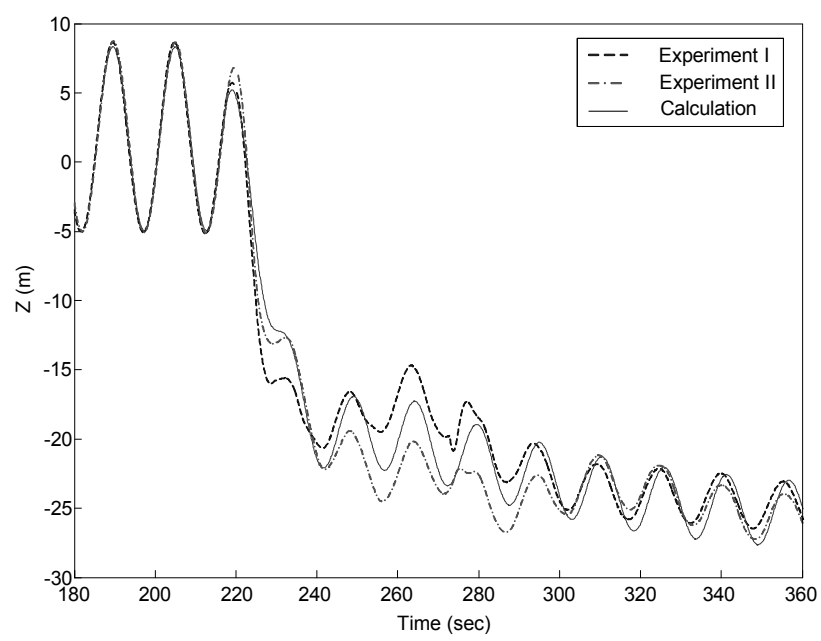

Figure 11: Validation of the buoy drop motion compared to model test results.

\subsection{Disconnected spider buoy response}

The disconnected spider buoy motion using the model presented in Figure 10 was studied for a number of 100-year cyclone conditions (Hs of $12.6 \mathrm{~m}$, peak period of $12.6 \mathrm{~s}$ ) to ensure buoy, mooring and riser system performance. Figure 12 compares the results obtained for the spider buoy motion (X-Z) envelope predicted by the numerical model and the model test of the disconnected system for a regular wave of height $20.9 \mathrm{~m}$ and period $12.9 \mathrm{~s}$. As seen in the figure the comparison is excellent allowing us to use the numerical model to study situations and cases not represented by the available model test data.

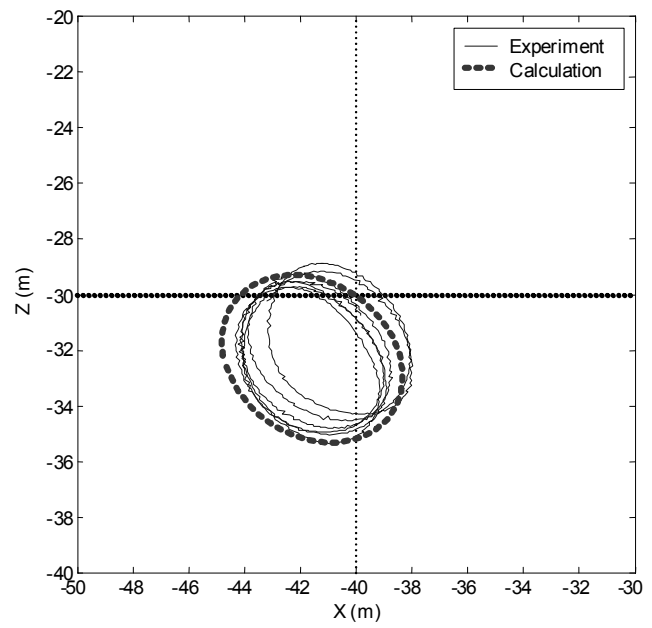

Figure 12: Disconnected buoy motion envelope comparison. 


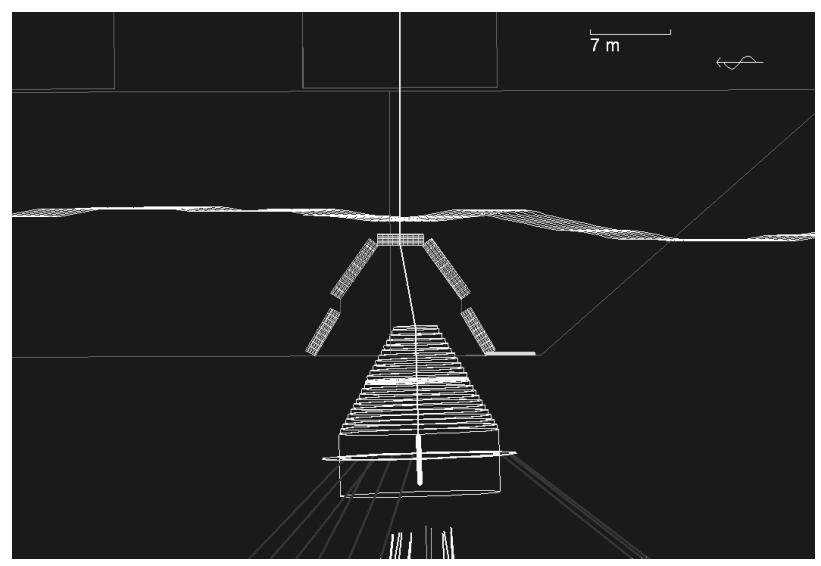

Figure 13: Numerical modelling of the buoy reconnection by considering turret/buoy contact with elastic blocks for the turret.

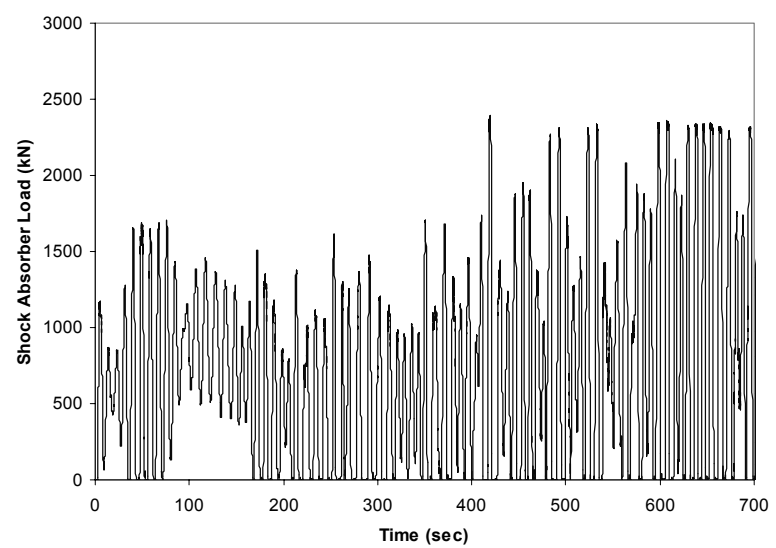

Figure 14: Estimation of the retrieval line load during reconnection.

\subsection{Analysis of spider buoy reconnect}

The analysis of the spider buoy reconnection is a very important aspect of the DTM design and operational efficiency of the FPSO. The Stybarrow system is designed to allow reconnection in significant wave height of $3 \mathrm{~m}$ without any assistance from other vessels. This requires accurate estimation of the relative FPSO - spider buoy responses during the entire retrieval scenario to ensure correct definition of lower turret and upper spider buoy geometry, winch sizing and retrieval lines loads, and sizing of the various fenders. The numerical model was developed in OrcaFlex and includes a detailed model of the FPSO with the retrieval winch and line modelled in addition to the spider buoy model presented in Figure 10. Figure 13 presents the details of the numerical model around the lower turret-spider buoy interface. The simulation (and model test) is then run 
using a fully-coupled model of the system, free to respond to the environmental conditions associated with a maximum reconnection seastate of $\mathrm{Hs} 3.0 \mathrm{~m}$.

Figures 14 and 15 present the retrieval load history from simulation and model tests respectively in irregular seas. Due to differences in modelling the shock absorber in the numerical model and model tests (simplified), speed of spider buoy retrieval, and the differences in wave realizations, the time histories of response cannot be compared directly but in a more qualitative manner. The figures show the estimation of the load history and system responses from the numerical model are very similar to that from the model tests, again confirming the accuracy of the numerical model.

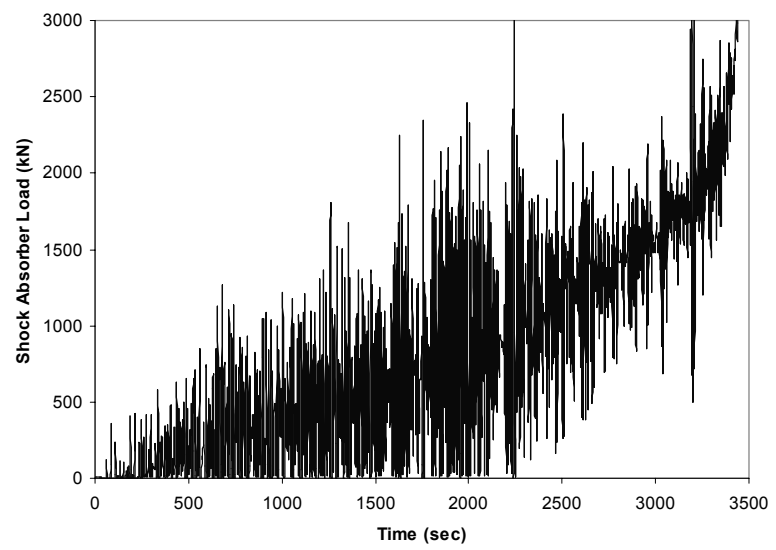

Figure 15: Experimental results of the retrieval line load during reconnection.

\section{Summary and conclusions}

The paper presents a general description of disconnectable turret moored FPSOs, and identifies some key deign parameters that need to be accounted for in the development of deep water DTM systems, based on the authors experience with analyzing and designing the Stybarrow FPSO in $825 \mathrm{~m}$ of water. In addition the paper presents a detailed description of the numerical modelling of an FPSO with a DTM system for deep water. Comparisons are made between the results from the numerical analysis and model tests conducted in an ocean basin for various stages of DTM disconnection and reconnection to validate the results obtained from the numerical analysis.

The paper demonstrates that rigorous development of a validated numerical model of the FPSO and spider buoy, mooring and riser system can be used effectively to analyze and design the system for various disconnect and reconnect scenarios. This allows the system to be optimized based on system and field specific requirements and to develop accurate criteria for operation of the system. 


\section{References}

[1] Duggal, A.S., Lindblade, S., Kwei, T. \& Young, J., Disconnectable turretmoored FPSOs - A reliable deep water floating production system for the Gulf of Mexico. Proc. of Deep Offshore Technology Int. Conf. and Exhibition, DOT, 2006.

[2] Luo, Y., Disconnectable FPSO's for Gulf of Mexico. Proc. of Deep Offshore Technology Int. Conf. and Exhibition, DOT, 2006.

[3] Howell, G.B., Duggal, A.S., \& Lever, G.V., The Terra Nova turret mooring system. Proc. Offshore Technology Conference, OTC 13020, 2001

[4] Duggal, A.S., Heyl, C.N. \& Vance, G.P., Global analysis of the Terra Nova turret mooring system. Proc. Offshore Technology Conference, OTC 11914, 2000.

[5] Ryu, S., Duggal, A.S., Heyl, C.N. \& Liu, Y., Prediction of deepwater oil offloading buoy response and experimental validation. Int. J. Offshore and Polar Engineering, 16(4), pp. 290-296, 2006. 